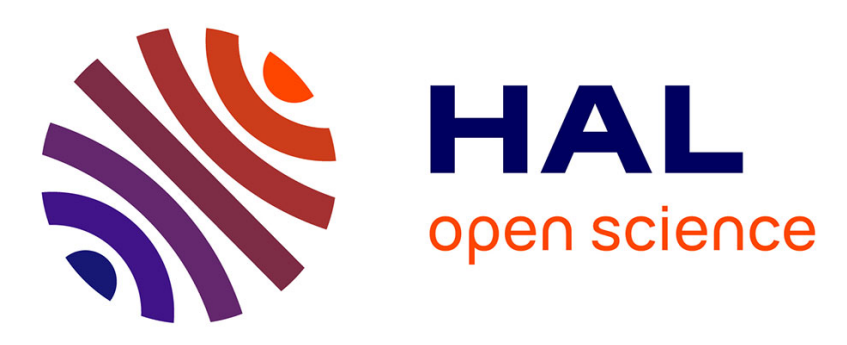

\title{
RC infilling of existing RC structures for seismic retrofitting
}

\author{
Christis Chrysostomou, Nicholas Kyriakides, Panagiotis Kotronis, Elpida \\ Georgiou
}

\section{- To cite this version:}

Christis Chrysostomou, Nicholas Kyriakides, Panagiotis Kotronis, Elpida Georgiou. RC infilling of existing RC structures for seismic retrofitting. 2nd European Conference on Earthquake Engineering and Seismology, Aug 2014, Istanbul, Turkey. hal-01080302

\section{HAL Id: hal-01080302 \\ https://hal.science/hal-01080302}

Submitted on 13 Jun 2019

HAL is a multi-disciplinary open access archive for the deposit and dissemination of scientific research documents, whether they are published or not. The documents may come from teaching and research institutions in France or abroad, or from public or private research centers.
L'archive ouverte pluridisciplinaire HAL, est destinée au dépôt et à la diffusion de documents scientifiques de niveau recherche, publiés ou non, émanant des établissements d'enseignement et de recherche français ou étrangers, des laboratoires publics ou privés. 


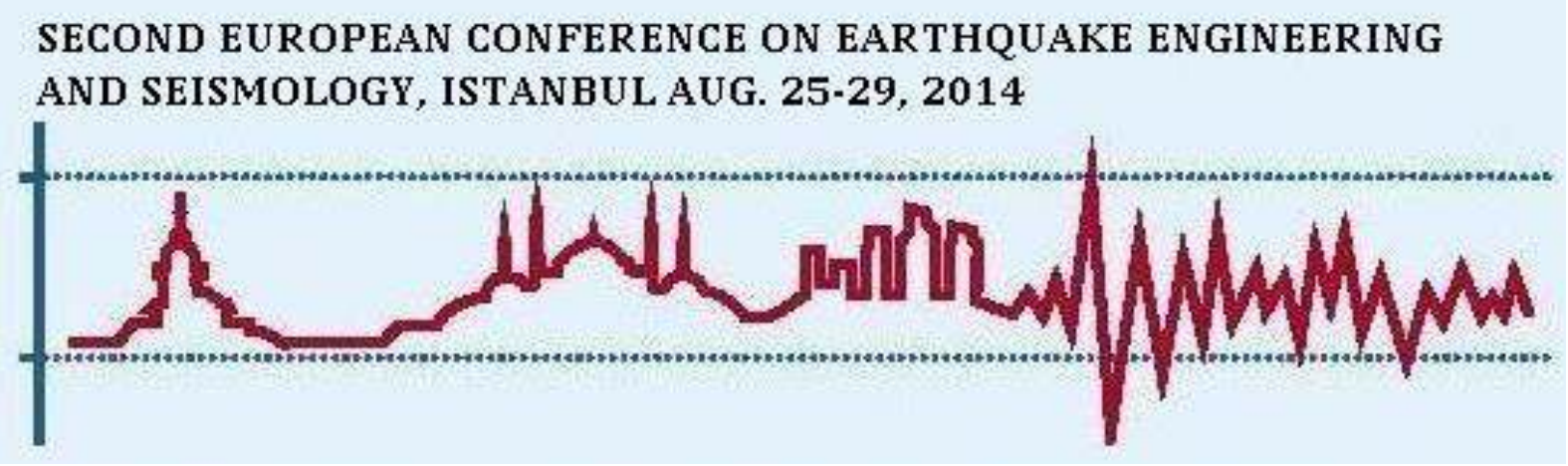

\title{
RC INFILLING OF EXISTING RC STRUCTURES FOR SEISMIC RETROFITTING
}

\author{
Christis Z. CHRYSOSTOMOU ${ }^{1}$, Nicholas KYRIAKIDES ${ }^{2}$, Panagiotis KOTRONIS ${ }^{3}$ and \\ Elpida GEORGIOU ${ }^{4}$
}

\begin{abstract}
The effectiveness of seismic retrofitting of multi-storey multi-bay RC-frame buildings by converting selected bays into new walls through infilling with reinforced concrete (RC) was studied experimentally at the ELSA facility of the Joint Research Centre (JRC) in Ispra (Italy).

A full-scale model was tested with the pseudo-dynamic (PsD) method and consisted of two four-storey $(12 \mathrm{~m}$ tall) three-bay $(8.5 \mathrm{~m}$ long) parallel frames linked through $0.15 \mathrm{~m}$ slabs with the central bay $(2.5 \mathrm{~m})$ infilled with a RC wall. The frames were designed and detailed for gravity loads only and are typical of similar frames built in Cyprus in the 1970's. Different connection details and reinforcement percentages for the two infilled frames were used in order to study their effects in determining structural response. In order to analytically simulate the experimental response, two mathematical models were formulated differing at the level of modelling. The first model is a micromodel based on 2D finite elements while the second is a 3-D macro-model with line elements to model the bounding frame and shear wall elements to model the walls. In this paper the experimental model is described and experimental results are presented along with conclusions for the behaviour of the frame. Then, the two analytical models described above are presented along with comparison of the analytical results to the experimental ones. Finally, conclusions are drawn regarding the effectiveness of the analytical models to capture the behaviour of the proposed structural system.
\end{abstract}

\section{INTRODUCTION}

The most effective and economic method for retrofitting multi-storey RC buildings is the construction of new walls, especially those with pilotis (soft-storey). Their structural and economic effectiveness increases when selected bays of an existing RC frame are fully infilled.

Most of the experimental research work performed in the last decades covers sufficiently the other frequently used types of retrofitting - in particular the use of fibre reinforced polymers (FRP) and the concrete jackets. There is no adequate experimental research work on the use of RC infill walls and most research has mainly targeted on what is feasible: testing of one- to two-storey specimens due to the practical difficulties of testing large specimens with high resistance. So, data is lacking for taller full-scale specimens that reflect real applications.

Regarding to code provisions, Eurocode 8 - Part 3 fully covers retrofitting with FRP or concrete jackets, while it does not refer at all to new walls created by infilling frame bays. Other guidelines, like KANEPE (2012) in Greece, refer to the design of such walls but only in terms of forces, without

\footnotetext{
${ }^{1}$ Associate Professor, Cyprus University of Technology, Limassol, c.chrysostomou@cut.ac.cy

${ }^{2}$ Post-Doctoral Researcher, Cyprus University of Technology, Limassol, nicholas.kyriakides@cut.ac.cy

${ }^{3}$ Professor, LUNAM Université, Ecole Centrale de Nantes, Nante, Panagiotis.Kotronis@ec-nantes.fr

${ }^{4} \mathrm{PhD}$ Candidate, Cyprus University of Technology, Limassol, es.georgiou@edu.cut.ac.cy
} 
providing tools for calculation of their characteristic deformations (at yield and failure) and stiffness, unless the infill wall can be considered integral with the bounding frame. The inadequacy of design codes in this respect is due to our poor knowledge of the behaviour of walls created by infilling with $\mathrm{RC}$ a bay of an existing frame.

To the present day, research on RC frames converted into walls by infilling with $\mathrm{RC}$ has been carried out almost exclusively in Japan and Turkey. The failure mode of all the experiments in Japan was in shear (including sliding at the interface). The results show that although a deformable connection gives a somewhat reduced strength with respect to the monolithic case, it considerably increases the ultimate deformation of the retrofitted structure. Regarding the specimens tested in Turkey, in most of the cases the single storey walls failed in shear, while the two storey walls failed by a combination of flexure and shear sliding at the base.

The test specimens used in the experiments correspond to walls with failure modes dominated by shear, with low aspect ratios. They are not representative of a multi-storey and slender wall since their behaviour and failure mode is dominated by shear. In fact, in real life bending controls the failure mode of multi-storey slender walls and the design is governed by the formation of a plastic hinge at the base. In such a case, shear will not have a detrimental effect on its behaviour and on its energy dissipation capacity. In addition, the higher modes of vibration of the structure are not taken into account although it has been shown numerically (Keinzel 1990, Eibl and Keinzel 1988) that higher modes may increase significantly the shears at the upper floors of a wall after the formation of a plastic hinge at the base. This aspect has never been studied experimentally even in integral walls, because their height and number of storeys was not large enough to allow higher mode inelastic response. One more common element of past tests is the smaller thickness of the RC infill wall relative to the width of the frame members. Consequently, the weak link of the structural system is either the infill wall in diagonal compression, or its connection with the surrounding frame.

In order to start filling the gap of knowledge regarding infilling of existing RC frames with RC walls, the effectiveness of seismic retrofitting of multi-storey multi-bay RC-frame buildings by converting selected bays into new walls through infilling with RC was studied experimentally at the Elsa Laboratory of Structural Assessment (ELSA) facility at JRC, in Ispra. The research was under the project "Seismic Engineering Research Infrastructures for European Synergies" (SERIES), financed by the Seventh Framework Programme of the European Commission. The consortium consisted of the Cyprus University of Technology (co-ordinator), the Ecole Central de Nantes, DENCO, the ELSA laboratory at JRC Ispra and the University of Cyprus. In the first part of the paper the design of the bare-frame specimen is presented and in the second part the details of the design of the RC infills are given. Then, the results of the testing campaign are presented along with analytical simulations. A 3-D macro model and a 2D finite element model were developed and are presented for comparison purposes and conclusions are drawn.

\section{DESCRIPTION OF SPECIMEN}

The specimen was designed based on a four-storey prototype building structure consisting of four three-bay frames spaced at 6 meters, with RC infilling of the exterior frames only. The specimen was designed at full-scale to represent the two exterior frames of the prototype structure, spaced at $6 \mathrm{~m}$ and linked by $0.15 \mathrm{~m}$ thick RC slab (Fig. 1b). The centre-line length dimension of the specimen was $8.5 \mathrm{~m}$ (central bay $2.5 \mathrm{~m}$ and the two exterior bays $3.0 \mathrm{~m}$ ), the storey height $3.0 \mathrm{~m}$, and the total height of the specimen (excluding the foundation) about $12.0 \mathrm{~m}$ (Fig. 1a).

The dimensions of the columns were $0.25 \mathrm{~m}$ by $0.40 \mathrm{~m}$ with the long dimension along the plane of loading, while those of the beams $0.25 \mathrm{~m}$ by $0.50 \mathrm{~m}$ (for both along the plane of the frame and perpendicular to it). 


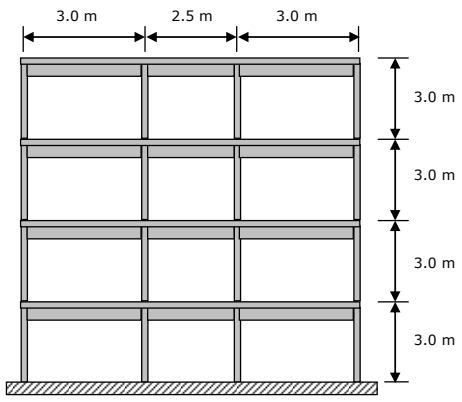

(a)

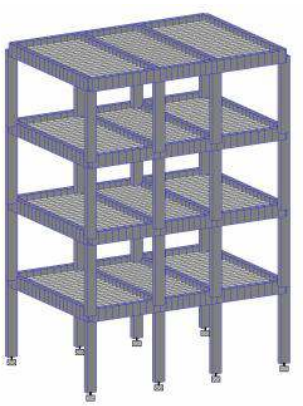

(b)

Figure 1. Dimensions and layout of the full-scale specimen without the RC infill

The proposed structure represents typical construction of the late 70's and beginning of the 80's in Cyprus. At that time there were no provisions for earthquake loading, so the structures were designed for gravity loads only. There was no specific design standard and the authorities were accepting any standard that was acceptable to other countries such as CP110 (BSI, 1972) and BS8110 (1983), DIN, Greek Code, US code etc. For the mock-up design it was decided to use the provisions of BS8110 which are very close to those of CP110 with very minor differences.

The material properties used in the mock-up were constrained by the availability of materials in the Italian and European market. It was finally decided to use concrete $\mathrm{C} 20 / 25$ for both the frame and the walls, of unit weight $25 \mathrm{kN} / \mathrm{m}^{3}$ and modulus of elasticity, E=30,000 MPa. The yield strength of the ribbed bar reinforcing steel was $f_{y k}=400 \mathrm{MPa}$ for both bending and shear reinforcement of the frame members and the slab, while for the RC infill and the dowels to be used for connecting the wall to the bounding frame members they yield strength was specified to fyk $=450 \mathrm{MPa}$. The $400 \mathrm{MPa}$ characteristic yield strength steel represents the one used in Cyprus construction practice in the 1970's and 80 's, while the $450 \mathrm{MPa}$ was the closest available in the Italian market to substitute for the 500 MPa steel that was used in the walls for retrofitting such a structure.

The self-weight was calculated using the unit weight of concrete specified above. The imposed dead load including the load of masonry infill walls was $3 \mathrm{kN} / \mathrm{m}^{2}$, and the live load was $1.5 \mathrm{kN} / \mathrm{m}^{2}$. These loads were combined using partial factors of safety of 1.4 for self-weight and imposed deadload, and 1.6 for the live load. The material partial factors used were 1.5 for concrete and 1.15 for steel.

The reinforcement details of the beams and columns are shown in Fig. 2a and Fig. 2b, respectively. For the beams of the frame $4 \Phi 12$ bars were used for top and bottom reinforcement. The shear links were $\Phi 8$ were placed at $200 \mathrm{~mm}$ intervals starting at $50 \mathrm{~mm}$ from the face of the column. For the transverse beams $2 \Phi 20$ bars were used at the top and 5Ф20 at the bottom of each of the four transverse beams. The links were $\Phi 8$ spaced at $100 \mathrm{~mm}$ so as to make sure that no failure will take place in the transverse beams which were used to transfer the forces from the actuators to the frames. The columns were reinforced with 4Ф20 bars and were lapped for a length of $0.55 \mathrm{~m}$ measured from the top face of the slab (Fig. 2b). This represents a compression lap, in line with a design for gravity loads only, and it is expected to fail when subjected to tension. Shear links $\Phi 8$ were spaced at $200 \mathrm{~mm}$ in the column, starting at a distance of $50 \mathrm{~mm}$ from the top face of the slab.

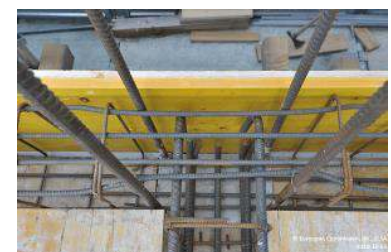

(a)

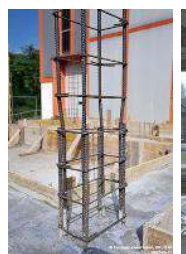

(b)

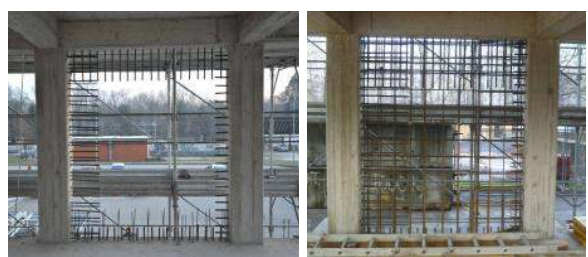

(c) (d)

Figure 2. (a) Reinforcement details for beams, (b) Reinforcement details for columns, (c) Dowels and starter bars. (d) Dowels, starter bars and web reinforcement

Similar to the transverse beams, the slab was considered as an element that will facilitate the transfer of forces from the actuators to the two parallel frames therefore the reinforcement was 
increased considerably. Although a nominal reinforcement of $\Phi 10 / 200$ was required by the standard, $\Phi 10 / 100$ was specified in order to ensure adequate transfer of forces. This was necessary to avoid damage to the slabs due to high concentration of forces from the lateral load application from the actuators during the PsD tests.

The walls in the two frames, which had a thickness of $0.25 \mathrm{~m}$ equal to the width of the beams and columns of the bounding frame, were reinforced with different amounts of reinforcement, with the north one being the stronger of the two, in order to facilitate the study of the effect of as many parameters as possible.

Two parameters were examined: a) the amount of web reinforcement in the walls and b) the connection detail between the wall and the bounding frame. Regarding the connection detail, two distinct connection details were used. In the first detail, the web bas are connected to the surrounding frame through lap splicing with the same diameter starter bars epoxy grouted into the fame members. Short dowels are then used in order to transfer the shear at the interface between the wall and the frame member. This detail was used to connect the wall at the bottom beam and right column at the $1^{\text {st }}$ and $2^{\text {nd }}$ floors of the north frame (Fig. 2c), starter bars shown here only for the bottom beam), while for the south frame it was used to connect the wall at the bottom beam of the $1^{\text {st }}$ and $2^{\text {nd }}$ floors, and the west and east columns of the $1^{\text {st }}$ and $2^{\text {nd }}$ floors, respectively.

In the second detail, longer dowels were used to double as dowels as well as for anchorage of the web panel to the surrounding frame, to this end, the dowels are considered as lap-spliced with the nearest - smaller diameter - web bars. However, in this case, the clear distance between the dowel and the nearest web bar, violates the maximum clear distance of $50 \mathrm{~mm}$ or $4 \Phi$ between lapped bars, specified in Eurocode 2 (CEN, 2004). This detail was used to connect the wall at the top beam and west column at the $1^{\text {st }}$ and $2^{\text {nd }}$ floors of the north wall (Fig. 2c), while for the south frame it was used to connect the wall at the top beam of the $1^{\text {st }}$ and $2^{\text {nd }}$ floors, and the east and west columns of the $1^{\text {st }}$ and $2^{\text {nd }}$ floors, respectively. In the $3^{\text {rd }}$ floor of both the north and south frames only the second detail was used, while for the $4^{\text {th }}$ floor only two dowels per wall interface were used to provide safety against falling of the wall out of plane. The completed wall reinforcement (including web, starter bars and dowels) for the $1^{\text {st }}$ floor of the northwall is shown in Fig. 2d. In all cases the dowels were positioned along the centerline of the elements (i.e. at $0.125 \mathrm{~m}$ from the face of the wall).

Since the lapping of the column reinforcement could take only compression, then it was obvious that there would be lap splice failure, which could be detrimental to the whole experiment. Therefore, in order to safeguard against this type of failure and allow the experiment to be performed without any premature failure, it was decided to reinforce the edges of the wall at the $1^{\text {st }}$ floor with three-sided CFRP for the height of $0.60 \mathrm{~m}$ from the base of the column.

\section{EXPERIMENTAL RESULTS AND SHORT DISCUSSION}

Displacement transducers were installed to measure local displacements in critical areas. In particular, transducers were placed to monitor: slip and crack opening between all walls and their bounding beams and columns, the displacements between the ground floor walls and the foundation beams, and the shear deformations of the two ground floor walls. Displacement transducers were also installed to measure at all storeys the vertical elongation of the bounding columns.

Inclinometers were used to measure the rotation of beams and columns at the first floor. They were placed at the centre joints and on beams and columns $30 \mathrm{~cm}$ away from the joints. Inclinometers were also placed at selected columns $30 \mathrm{~cm}$ above the foundation beam.

Heidenhain linear encoders were installed on two reference frames to measure the horizontal displacement of the two frames at each of the four floors in the direction of testing.

For the low level acceleration, the structure behaved very well. There were no visible cracks either on the columns or the walls. Some hairline cracks that appeared on the surface of the wall closed down when the experiment was finished. The maximum top storey displacement was $24 \mathrm{~mm}$ and the displacement in the opposite direction was $26 \mathrm{~mm}$. These displacements were the same for both the north and south frames, since the forces in the south frame were imposed in such a way so as to keep the displacements of the two frames equal, and hence avoid any torsional effects on the 
specimen. It was considered that both walls have reached their cracking moment, and this was the purpose of this experiment.

The $0.25 \mathrm{~g}$ test was performed the day after the first test, and it was designed to bring the specimen at its ultimate capacity. The maximum top storey displacement was $109 \mathrm{~mm}$ and the displacement in the opposite direction was $-93 \mathrm{~mm}$ (Fig. 3a). Some difference was observed in the base shear between the two frames. As it can be observed from Fig. 3b, the maximum base shear in the positive direction was $1074 \mathrm{kN}$ for the south frame and $1036 \mathrm{kN}$ for the north, which are about the same, while a negative base shear of $-843 \mathrm{kN}$ was recorded for the south frame and $-1011 \mathrm{kN}$ for the north one. This was an indication that the south frame has suffered some damage and it could not take further load. The only visual indication of this was a crack that opened in the ground beam at the base of the wall and the lap-splice failure of the outer column on the east side of the south frame. It should be noted that the presence of the CFRP on the bounding columns of the wall, have prevented a similar failure and it allowed the completion of the experiment.

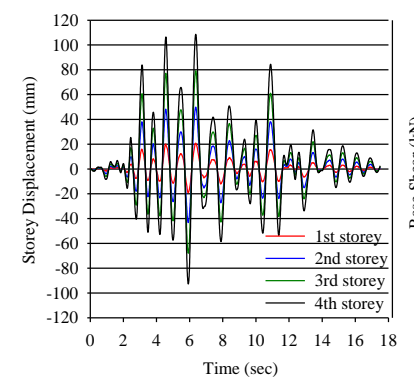

(a)

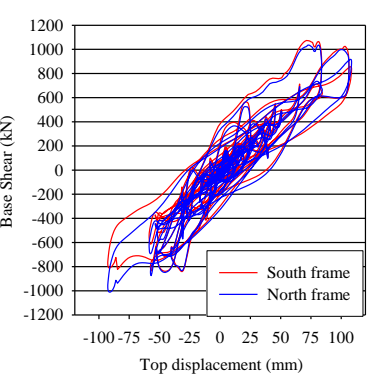

(b)

Figure 3. Experimental at $0.25 \mathrm{~g}$ acceleration (a) Variation of the storey displacements with time, (b) Base Shear versus top storey displacement for the north and south frames

Regarding general behaviour of the specimen it can be said that it withstood the loading imposed on it very well. There were no visible diagonal cracks on the walls, which behaved flexurally. In nearly all the columns a horizontal crack appeared at a height of $0.55 \mathrm{~m}$ where the lap-splice stopped, and in some cases there was spalling of the concrete cover. Some vertical cracks appeared at the connection between the beams and the columns, but there was no severe damage, despite the fact that there were no ductile connections in the structure. In general, the stronger north frame had an overall better behaviour compared to the south one, but the differences were minor.

Finally, in the "funeral" cyclic test a displacement history was imposed at the top storey (92, $92,89,-125,37,0 \mathrm{~mm}$ ) and a triangular distribution of forces was imposed. The objective of the test was to obtain a $20 \%$ reduction of the peak strength of the infill, so as to establish the strength envelope of the specimen. The base shear versus the top storey displacement is shown in Fig. 4. As it can be observed in the first cycle the structure could reach $92 \mathrm{~mm}$ in both directions. In the second cycle the attempt was to reach $125 \mathrm{~mm}$, but in the positive direction only $89 \mathrm{~mm}$ was possible to be reached, while in the negative direction $125 \mathrm{~mm}$ was reached. This though had as a result a sudden drop of the strength of the south frame from $838 \mathrm{kN}$ at $-110 \mathrm{~mm}$ to $553 \mathrm{kN}$ at a displacement of $-125 \mathrm{~mm}$. This amounts to a drop in strength of $34 \%$. After that, the displacement was reduced to $37 \mathrm{~mm}$ in the positive direction and from there to zero. Detailed presentation of the experimental model and testing campaign, as well as discussion of the results are given in Chrysostomou et al. (2013) and (2014).

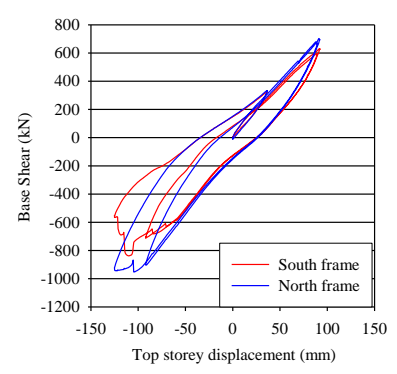

Figure 4. Base shear versus top storey displacement for the south and north wall for the cyclic test 


\section{D FINITE ELEMENT MODEL}

As already mentioned, during the experiments equal displacements were applied to the two frames in order to maintain a zero rotation along the horizontal plane of the floor. The loading being unidirectional, a 2D finite element model is first chosen. All the calculations presented in this section have been performed before the experiments ("blind" calculations). One frame is considered of width $0.25 \mathrm{~m}$, with $75000 \mathrm{~kg}$ per floor and a total weight of $1211 \mathrm{kN}$ at its base. The finite element code Cast3M developed at CEA in France is used for the calculations. Concrete is modelled using classical quadrilateral finite elements (Figure 5(a)) and horizontal and vertical reinforcement bars with truss elements (Figure 5(b)). Perfect bonding is assumed between concrete and steel, the existing structure and the RC infilling. Table 1 provides the distribution of the reinforcement bars in the finite element model. The FRP's are not considered.

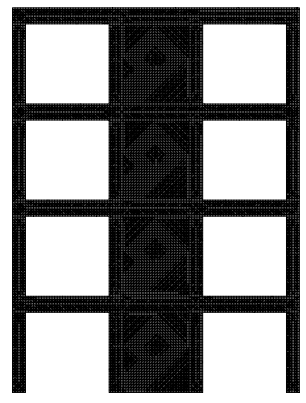

(a)

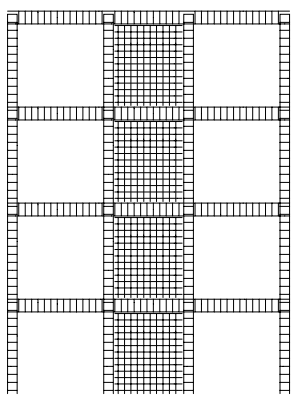

(b)

Figure 5. 2D finite element discretisation (a) concrete mesh (b) steel mesh

Table 1. 2D finite element model: distribution of reinforcement bars

\begin{tabular}{c|c}
\hline Beam (long.) & $4 \Phi 12$ (up), $4 \Phi 12$ (down) \\
\hline Beam (transv.) & $\Phi 8 / 200$ \\
\hline Column (transv.) & $2 \Phi 20$ (left), 2 $\Phi 20$ (right) \\
\hline Column (transv.) & $\Phi 8 / 200$ \\
\hline Wall (long.) & $\Phi 12 / 200$ (2 layers) \\
\hline Wall (transv.) & $\Phi 12 / 200$ (2 layers) \\
\hline
\end{tabular}

Results of the modal analysis are provided in Figure 6. The first mode, corresponding to flexion in plane dominates the behaviour of the structure.

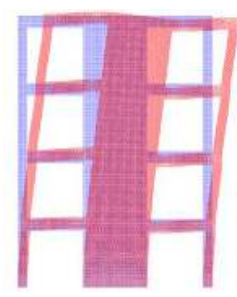

$\mathrm{f}_{1}=2.85 \mathrm{~Hz}$

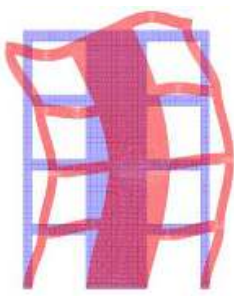

$\mathrm{f}_{2}=11.35 \mathrm{~Hz}$

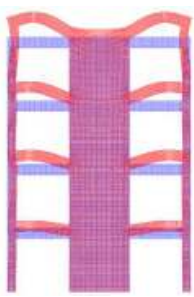

$\mathrm{f}=13.6 \mathrm{~Hz}$

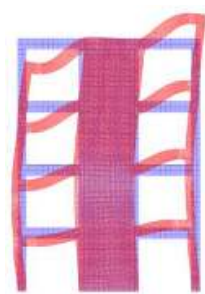

$\mathrm{f}_{4}=15.3 \mathrm{~Hz}$

Figure 6. 2D finite element model: the first four eigenmodes and the corresponding eigenfrequencies

Advanced constitutive laws, suitable for cyclic loadings are used for the materials. Concrete behaviour is reproduced using a damage mechanics law that takes into account the difference in traction and compression and the unilateral effect (opening and closing of cracks) (Faria et al. 1998). Steel is modelled using a classical plasticity law able to reproduce the Bauschinger effect (cinematic hardening) (Menegoto M, and Pinto P., 1973). The material parameters are introduced in Table 1. 
Table 1. 2D finite element model: material parameters

\begin{tabular}{c|c|c|c}
\hline Concrete & Parameters & Steel & Parameters \\
\hline Young's modulus & $20 \mathrm{E}+09 \mathrm{~Pa}$ & Young's modulus & 200E+09 Pa \\
\hline Poisson coefficient & 0.2 & Poisson coefficient & 0.3 \\
\hline Tension stress limit & $3.6 \mathrm{MPa}$ & Stress limit & $460 \mathrm{MPa}$ \\
\hline Tension deformation limit & $1.8 \mathrm{E}-04$ & Deformation limit & 0.0023 \\
\hline Compression stress limit & $33.8 \mathrm{MPa}$ & Stress ultimate limit & $515 \mathrm{MPa}$ \\
\hline Compression deformation limit & $-3.0 \mathrm{E}-03$ & Deformation ultimate limit & $\sim 0.25$ \\
\hline
\end{tabular}

Nonlinear calculations are performed considering a very low level of viscous Rayleigh damping $(0.25 \%)$. The implicit Newmark numerical algorithm is adopted for the time integration of the equation of motion and the classical Newton-Raphson algorithm for the nonlinear material behavior. Results are presented hereafter for $0.25 \mathrm{~g}$ (and for an earthquake signal of about $12 \mathrm{sec}$ ).

Figure 7 compares the numerical and the experimental results considering the displacements time histories at all floors. The performance of the "blind" numerical model is satisfactory in terms of maximum values and frequency content especially for the upper floors.
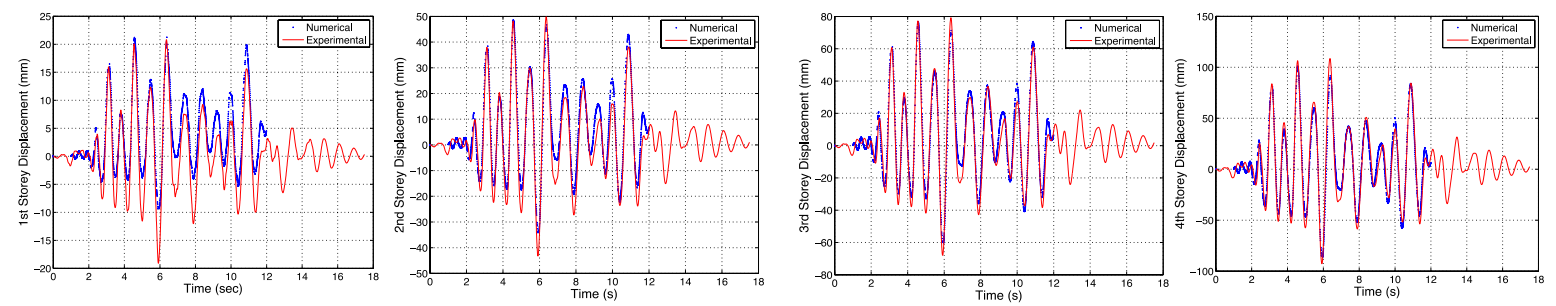

Figure 7. 2D finite element model $(0.25 \mathrm{~g})$ : displacements time history, experimental vs. numerical results

Figures 8 and 9 show the performance of the model in terms of base shear-top displacement and storey shear-interstorey drift at each floor. Results are particularly good for the upper floors. One can notice however that the model does not reproduce accurately the interstorey drift at the base.

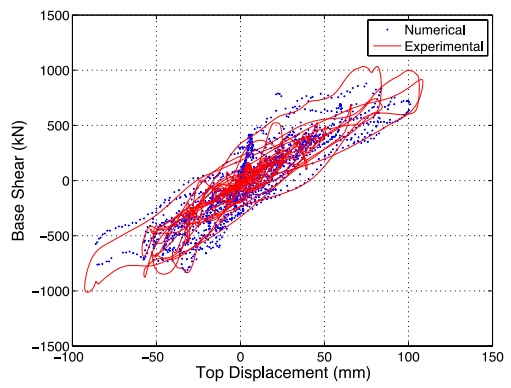

Figure 8. 2D finite element model $(0.25 \mathrm{~g})$ : Base shear - top displacement, experimental vs. numerical results
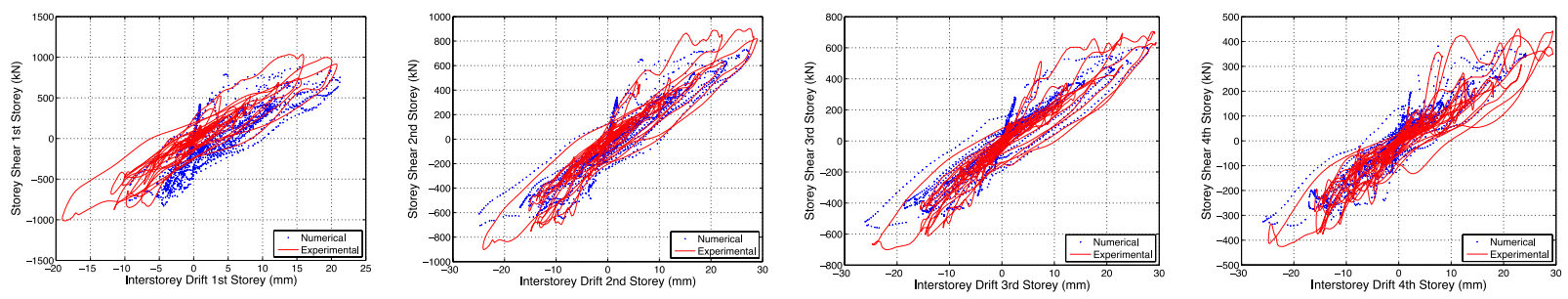

Figure 9. 2D finite element model $(0.25 \mathrm{~g})$ : Storey shear and interstorey drift, experimental vs. numerical results

The advantage when using continuum mechanics constitutive laws is that we have access to local results in terms of damage indicators, strains in the reinforcement bars etc. Figure 10 shows the damage variable due to traction (a) and to compression (b) for a loading of $0.25 \mathrm{~g}$. This damage index 
varies between 0 and 1 (from undamaged to completely damage section). We can distinguish the good behavior of the structure in terms of strong column-weak beam mechanism. However, the existence of damage due to compression at the bottom indicates that this level of loading is important and that for a higher level of PGA the vulnerability of the structure maybe at risk.

(a)

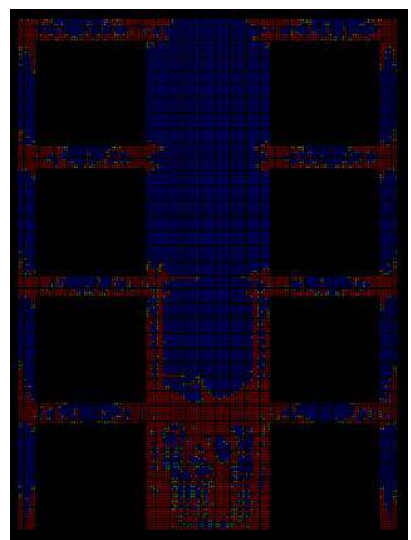

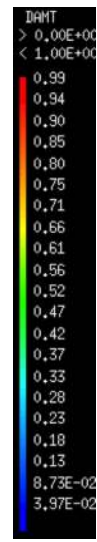

(b)

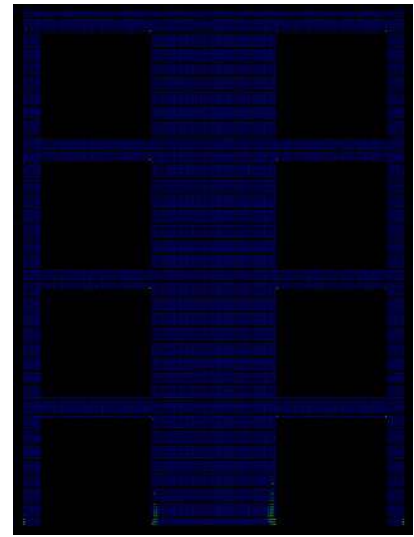

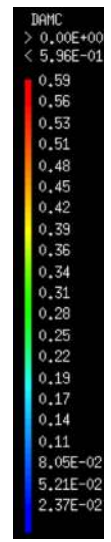

Figure 10. 2D finite element model (0.25g): Damage variable due to traction (a) and due to compression (b)

Finally, Figure 11 presents the distribution of stains in the horizontal and vertical reinforcement bars, in the frame and in the infill. Although not any steel bar has reached the ultimate strain limit ( 0.25), many have yielded. However, the small amount of damage due to compression seems to indicate that there is no risk of buckling at this level of the loading.

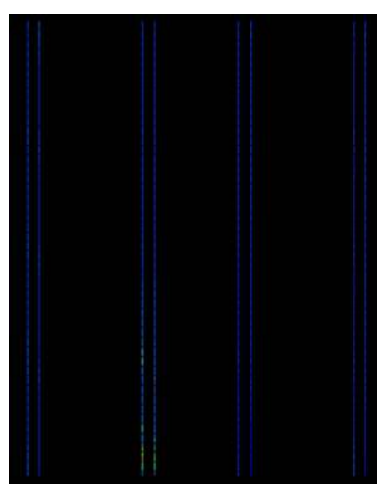

(a)

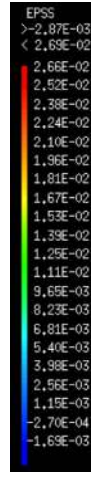

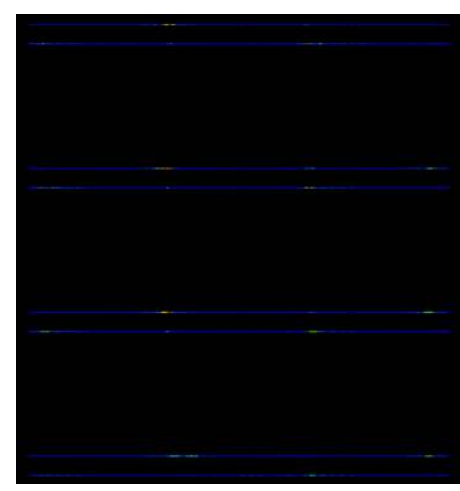

(b)

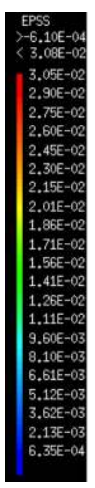

Figure 11. 2D finite element model (0.25g): Strain in steel (a) vertical bars in the frame (b) horizontal bars in the frame (c) vertical bars in the infill

\section{SIMPLE ANALYTICAL MODEL}

The analysis of the building was also conducted using a simple 3D analytical model based on line and shell elements. The purpose of this model was to observe the correlation of the analytical to the experimental results and examine the effect of modelling in increasing the accuracy of simulation. The simplicity in modelling results in less computational time and thus provides the opportunity to study the 3D behaviour of the building. The analytical model was created in SAP2000, which is used both for commercial and academic purposes, offers a friendly graphical interface, and includes non-linear models both for line and shell elements. A view of the model is shown in Figure 12. 


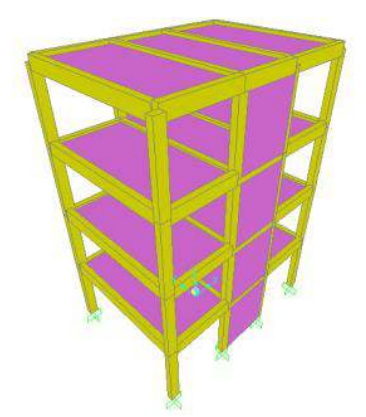

Figure 12. 3D view of the analytical model in SAP2000

The modelling of the building was assembled using line fibre elements for the columns which are expected to behave non-linearly as observed during the experiment. The column cross-section described earlier in the paper was discretised in 8 concrete fibres and 4 steel ones as shown in Figure 13. The fibre element properties were distributed along the length of the column elements.

The Takeda (1970) model was used to describe the non-linear properties of concrete including cracking. The Mander (1984) unconfined concrete model was used to describe the monotonic stressstrain relationship. In the case of the steel reinforcement, kinematic hysteretic type was assumed. The monotonic laws for both materials are shown in Figure 14.

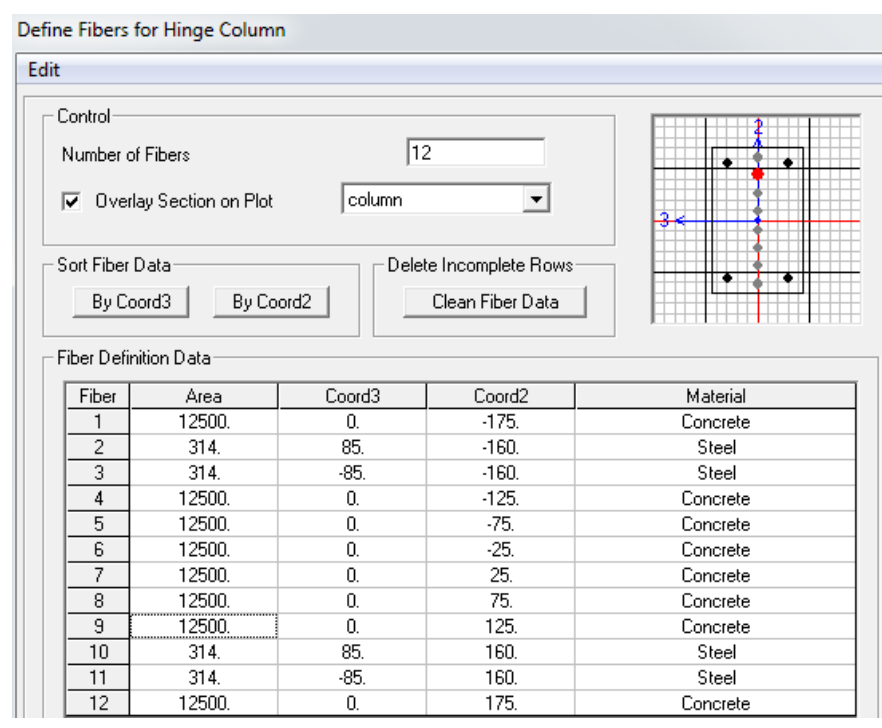

Figure 13. Characteristics of fibres of column section

Both longitudinal and cross beams were modelled using elastic properties since non-linearities were not observed in these elements. In order to account for the reduction in stiffness due to cracking at the $0.25 \mathrm{~g}$ test, a $10 \%$ reduced elastic stiffness was used.

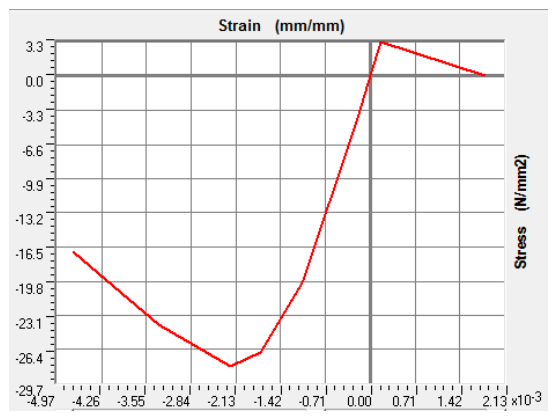

(a)

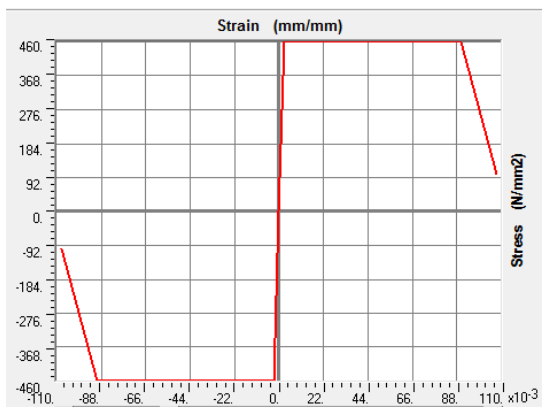

(b)

Figure 14. Monotonic laws for (a) concrete (b) steel reinforcement 
$\mathrm{RC}$ infill walls in the middle bay of the building were modelled using a non-linear fibre shell element. The discretization of the wall cross-section was created automatically and accounted both for the in and out of plane properties of the wall. The steel mesh reinforcement of each wall was modelled based on the corresponding detail as described in Chrysostomou (2014) in order to account for the strength reduction in higher floors. The discretization for the first floor wall is shown in Figure 15. The same material constitutive laws were applied as for the column line elements. A single shell element was used to model the wall in each floor. The walls were assumed to be rigidly connected to the 4 corners of the bounding frame elements in each floor therefore no relative movement between the walls and the bounding frame was allowed, which is one of the shortcomings of the model.

Based on the correlation of the results, it will be concluded whether such a movement took place or if the connection of the wall to the bounding frame using closely spaced dowels was close to rigid.

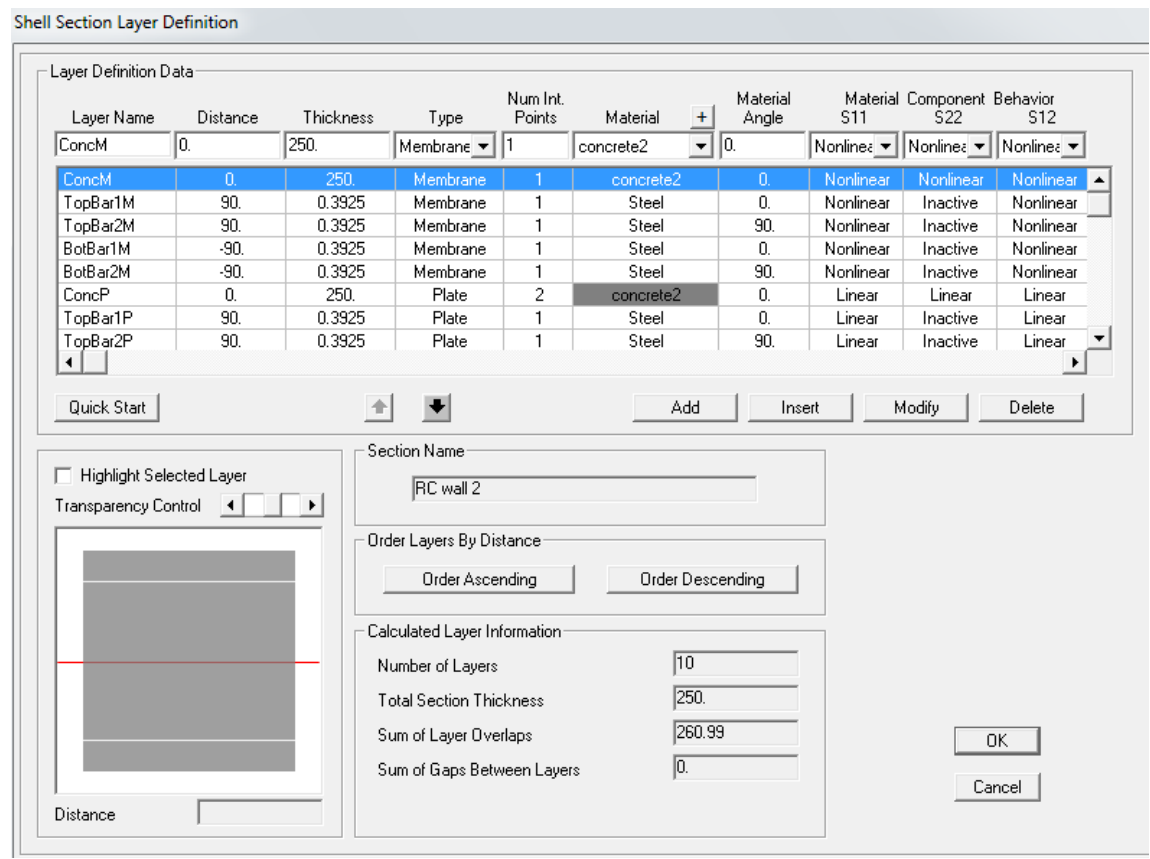

Figure 15. Discretization of shell RC wall section for the $1^{\text {st }}$ floor wall.

The full mass of the original building (600 Tonnes) was applied on the model as lumped masses on all the nodes. Floor finishes and masonry wall loading were modelled using floor loading. The analytical period at the beginning of the $0.25 \mathrm{~g}$ test was equal to $0.48 \mathrm{sec}$., which is very close to the experimentally recorded one at the beginning of the test that was approximately equal to $0.50 \mathrm{sec}$. The evolution of the $1^{\text {st }}$ mode frequency during the 0.25 test is shown in Figure 16.

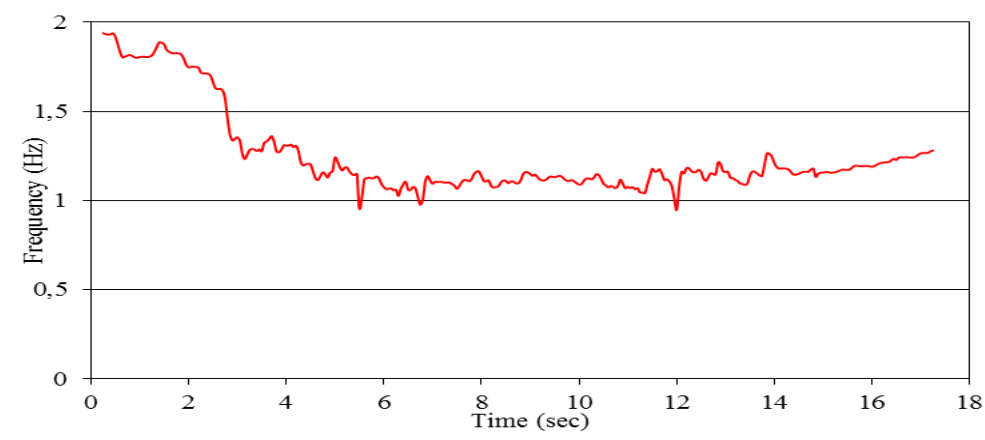

Figure 16. Evolution of frequency of the tested building during the $0.25 \mathrm{~g}$ test 
Similar to the 2D finite element model, a $0.25 \%$ viscous damping was used to account for the limited damping in the building during the slow process of pseudo-dynamic testing. The hysteretic damping introduced by the non-linear behaviour of the elements was introduced by the Takeda model and the steel reinforcement hysteretic model.

The comparison of experimental to the analytical history of top storey displacements is shown in Figure 17. It can be easily concluded that the analytical model captures with high accuracy the behaviour of the tested building. Both the evolution in period and strength during the experiment are very well simulated in the model and so is the non-linear behaviour of the building.

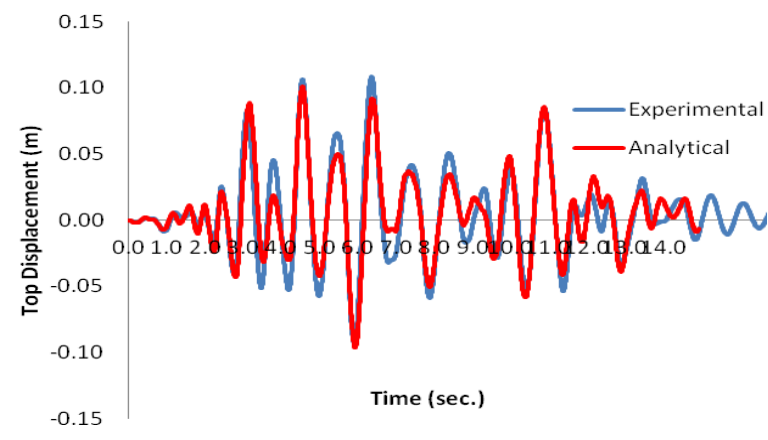

Figure 17. Comparison of top storey displacement history for the $0.25 \mathrm{~g}$ test

To examine the correlation of the base shear force, energy dissipation and stiffness between the experimental and analytical model, the base shear vs. top displacement hysteretic curves are plotted in figure 18.

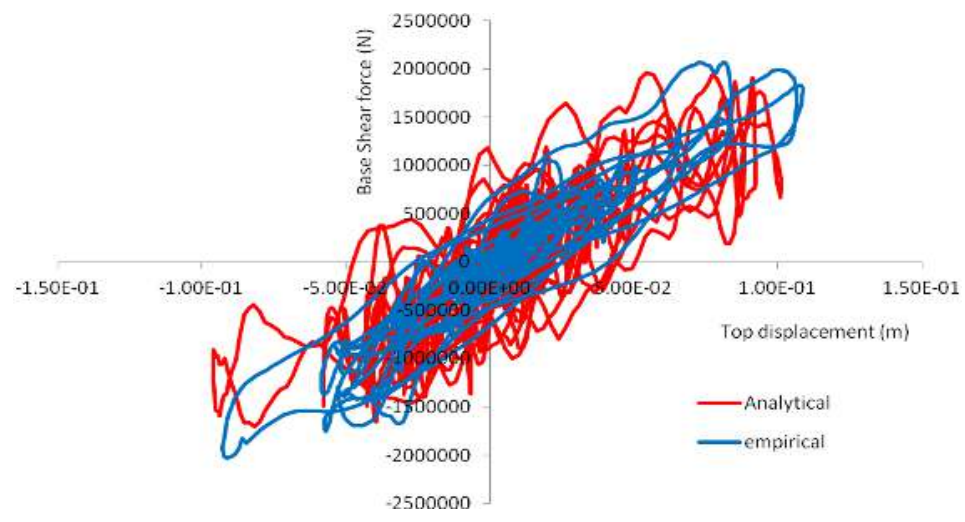

Figure 18. Comparison of base shear vs. top storey displacement history for the $0.25 \mathrm{~g}$ test

From the comparison in Figure 18 it appears that the base shear in the analytical model simulates closely the experimental one. Also, the stiffness of the analytical model defined using the slope of the hysteretic loop response is close to the experimental one. In the case of energy dissipation, it appears that the analytical model absorbs slightly higher levels of energy (probably more damage) based on the width of the hysteretic loop response.

\section{CONCLUSIONS}

The purpose of the paper was to examine the capabilities of a $2 \mathrm{D}$ finite element model and a 3D simple fibre model to simulate the experimental non-linear behaviour of a 4-storey RC building strengthened with RC infill walls. Both models seem to simulate the experimental behaviour with very good levels of accuracy which strengthens the assumption that the connection between the walls and the bounding frame was very close to monolithic. It should be stressed out that if less dowels were used at the connection, relative movement might have took place, which would require modelling of 
the interface between the infill and the bounding frame in order to capture this behaviour. The 2D model, although it was based on "blind" calculations, it managed to give also local results, which were compatible with the observed behaviour of the specimen during testing.

\section{ACKNOWLEDGMENT}

This project $\triangle \mathrm{IAKPATIKE} \mathrm{L} / \mathrm{KY}-\mathrm{\Gamma A} / 0512 / 02$ is funded under DESMI 2009-10 of the Research Promotion Foundation of Cyprus and by the Cyprus Government and the European Regional Development Fund.

\section{REFERENCES}

BS8110 (1983) Structural use of concrete, Code of Practice for Design and Construction, Part 1, The Council for Codes of Practice, British Standard Institution, London

BSI (1972) CP110-The structural use of concrete, Part 1, The Council for Codes of Practice, British Standards Institution, London

Cast3M, Site web of the finite element code Cast3M, http://www-cast3m.cea.fr

CEN (2004) Eurocode 2: Design of concrete structures-Part 1: General rules and rules for buildings (EN-1992-11), Comité Européen De Normalisation

Chrysostomou C Z, Poljansek M, Kyriakides N, Molina J, Taucer F (2013) "Pseudo-dynamic tests on a full-scale 4-storey RC frame seismically retrofitted with RC infilling," Structural Engineering International Journal of IABSE, 23(2):159-166

Chrysostomou C Z, Kyriakides N C, Poljansek M, Molina J, Taucer F (2014) Chapter 17: RC Infilling of Existing RC Structures for Seismic Retrofitting, Seismic Evaluation and Rehabilitation of Structures, Geotechnical, Geological and Earthquake Engineering 26, Springer International Publishing, DOI 10.1007/978-3-319-00458-7_17

Eibl J and Keintzel E (1988) "Seismic shear forces in cantilever shear walls", 9th World Conference in Earthquake Engineering

Faria, R., Oliver, J., \& Cervera, M. (1998). A strain-based plastic viscous-damage model for massive concrete structures. International Journal of Solids and Structures, 35(14), 1533-1558. doi:10.1016/S00207683(97)00119-4

KANEPE (2012) Code for Intervention in Reinforced Concrete Buildings, Earthquake Planning and Protection Organization (OASP)

Keintzel E, (1990) "Seismic design shear forces in reinforced concrete cantilever shear wall structures", European J. of Earthquake Engineering. 3:1, 7-16

Mander, J.B., M.J.N. Priestley, and R. Park 1984. Theoretical Stress-Strain Model for Confined Concrete. Journal of Struc-tural Engineering. ASCE. 114(3). 1804-1826

Menegoto M, Pinto P (1973) Method of analysis of cyclically loaded reinforced concrete plane frames including changes in geometry and non-elastic behaviour of elements under combined normal force and bending. In: IABSE Symposium on resistance and ultimate deformability of structures acted on by well-defined repeated loads, final report, Lisbon, p 328

Takeda T., Sozen M., and Nielsen N. (1970) Reinforced concrete response to simulated earthquakes, Journal of Structural Division (ASCE), 96, (12), 2557-2573 